\title{
Research on Brand Building Strategy of Agricultural Products Yajuan Sun ${ }^{1, a}$ \\ ${ }^{1}$ Xijing University, Xi'an, Shaanxi, 710123
}

\author{
Keywords: Agricultural Products, Brand Building Strategy, Economy Development
}

\begin{abstract}
In recent years, Chinese agricultural brands around the construction of a lot of useful exploration, established pollution-free food, green food, organic food as a priority to the development of the object. Since 2004, the central government has introduced five consecutive "one document", agricultural brand building has become a local government and agricultural leading enterprises to explore the hot issues. Agricultural brand building as an agricultural transformation and efficiency, farmers an important way to increase income, will play an active role in the realization of agricultural modernization. But the domestic brand of agricultural products research and practice, more limited to government planning and guidance. How to integrate the government planning strategy, product strategy, price strategy, channel strategy, promotion strategy and talent strategy in brand building will become an important subject of research on brand building of agricultural products in China. Based on the analysis of the macroscopic and microscopic influencing factors of the brand building of agricultural products in China, this paper constructs and analyzes the model of agricultural product brand construction by using the Chekland method.
\end{abstract}

\section{Introduction}

A brand is a business name, usually composed of elements such as words, symbols, signs, patterns, and colors. An enterprise is used to identify its own product or service, so as to distinguish it from a competitor's product or service. Different attributes, interests, values, personality, culture and customers constitute the connotation of the brand. The connotation and benefits of the brand Once the consumer recognition is easy to form brand loyalty, and then strengthen the brand's proprietary, this exclusive nature of the brand is conducive to the establishment and maintain its unique differentiation of competitive advantage. Once the agricultural products have their own brand, there will be the characteristics of the general merchandise brand, with distinctive characteristics, strong personality, representing a specific commodity attributes, reflecting a sense of value and culture. With the brand, consumers can easily identify the products and services of a seller or group of sellers, distinguishing it from the competitor's products or services. If the production of Mao Yang outside the Xinyang tea people generally do not recognize its value. Therefore, the creation of brands for agricultural products can make it different from other regions of similar agricultural products, to facilitate consumer identification and response. The creation of agricultural products brand is conducive to farmers to adjust the structure of agricultural production, production of quality products, improve agricultural production efficiency. Such as Shandong Zhangqiu by strengthening the standardized management of green onions, vigorously promote the standardization of green onions production, registration Zhangqiu onion geographical indications and other measures to create Zhangqiu green onion brand, making Zhangqiu onion sales price doubled year after year, the highest price from the initial technetium 0.6 yuan $/ \mathrm{kg}$ increased to the current 5 yuan $/ \mathrm{kg}$ or so, green onions net income of up to 2,500 yuan $/ 667 \mathrm{~m}^{2}$ above, onion agricultural income doubled.

\section{Analysis on the Problems Existing in the Construction of Agricultural Products Brand}

Low degree of organization of farmers, production and management scattered. Chinese rural areas of the main mode of production is the implementation of household contract responsibility system, the production scale is small, decentralized, low degree of organization of farmers cooperation, small farmers awareness, lack of long-term vision, market awareness, brand awareness is relatively 
weak. Brand in the field of production and business areas and not enough attention, many farmers producers and operators of the business philosophy, packaging and sales are not new ideas, often brand agriculture trademark agriculture. In particular, farmers scattered business, a low degree of organization even if the registration of the trademark brand, but also unable to carry out publicity and the corresponding market development, resulting in increased awareness of trademark awareness, can not play the role of the brand. Low degree of agricultural standardization is uneven quality of agricultural products brand. The core of agricultural product brand building is brand quality construction. The implementation of agricultural standardization is the guarantee of agricultural brand. However, compared with foreign developed countries, Chinese agricultural standardization level is low, the implementation of agricultural standards lag. Many places only focus on standard-setting, and not pay attention to the implementation of standards, production, processing and other links are still conventional production. Some only focus on prenatal, production standards in the implementation, while ignoring the implementation of postpartum standards, production, processing, circulation can not achieve all aspects of organic integration. Which caused the quality of agricultural products at different levels, seriously hampered the cultivation and development of well-known agricultural products brand.

Only focus on the number of agricultural products brand, ignore the strong brand. In recent years, the number of agricultural products registered in China more and more, such as the end of 2007 in Shandong Province, the province has pollution-free agricultural products up to 2080. The increase in the brand has led to the rapid development of local agriculture. However, in the domestic and foreign markets to enjoy the visibility and the formation of the scale of small, less brand, leading to licensing unknown, it is difficult to obtain great development, but can not create well-known brands. Eventually leading to the competitiveness of agricultural products is not strong, leading to low income of agricultural products, farmers do not increase income.

The brand management mechanism of agricultural products is not perfect. Agricultural brand resources can be shared, but by the brand of intangible assets and other interests of the mechanism, the government, enterprises and farmers to share difficult to coordinate. The development of special-purpose agricultural products is still in a state of self-government. Coupled with the characteristics of decentralized management, market mechanism is imperfect, disorderly competition, the brand is difficult to integrate. In addition, the registration of agricultural products trademark re-reported, selection, and ignore the follow-up tracking management, ignoring the quality of brand planning and publicity is not conducive to establish a brand image. Moreover, the protection of agricultural products brand is not enough, often a variety of theft of agricultural brand phenomenon, seriously damaged the interests of product operators.

The marketing mechanism of agricultural products is not perfect. Agricultural brand marketing is an important part of the product to achieve the value of goods. The ultimate goal of production is to carry out brand sales. But the product sales are bad, it is difficult to achieve the established income, farmers increase difficulties. Many places, under the government's strong propaganda, to declare the local agricultural brand, farmers produce agricultural products of high enthusiasm, but ignored the product marketing links, product sales to farmers caused serious losses.

\section{Regional Branding Strategy for Agricultural Products}

Domestic regional name, special, excellent agricultural products a lot, but for a long time, did not pay attention to the brand of these products, the lack of brand products, can not be widely recognized by the market, the geographical advantages of resources can not play, Have a good income. This requires the government from the macro level to create brand awareness awareness, the brand building as an important part of the new rural economic construction, from the financing and financial subsidies to the leading enterprises to give policy support for brand building. With the government's policy support, agricultural production and operation enterprises should "fully understand the implementation of brand strategy in the production and operation of agricultural products in the important role, establish a new concept of agricultural development, from the traditional concept of agricultural marketing to marketing concept, enhance brand awareness, 
Recognize the creation of the brand is to enhance the grade of agricultural products, improve market competitiveness, to achieve market optimization, efficiency optimization of an important way "[2]. Domestic regions have their own strong national culture, which is our valuable resource to create the brand. Enterprises can combine the regional unique history and culture to create regional characteristics of green brand image. Should be brand building as a business to capture the market, to win the impression of consumers, shaping the image of a good corporate image. In the government's propaganda, leading enterprises to let farmers in the brand management in the tangible benefits, so that farmers appreciate the brand effect of agricultural products brought about by the huge economic benefits, so that farmers establish brand awareness, to overcome the small farmers business ideas, in agricultural production With the implementation of brand building strategy.

Agricultural brand building is to obtain long-term competitive advantage for the purpose, need to continue to invest in construction and development costs. In the book "Strategic Economics", D. Besanko points out three specific economies of scale and economies of scale associated with areas other than production: (1) economies of scale and economies in the economy; (2) economies of scale and economies of scope in advertising; and (3) economies of scale and economies in research and development. The production of agricultural products is labor-intensive production, its production economies of scale and scope of economic effects are not particularly obvious, but not without. And the above and outside the production area of the three aspects of economies of scale and scope of economic effects can be in the agricultural brand building can be fully reflected. Because the production of branded agricultural products needs to purchase qualified means of production, need to spend advertising costs, need to bear the quality of agricultural technology development costs. The success of the brand to create and maintain a good brand reputation and corporate image, based on the same brand under the same brand of other agricultural products development is more able to produce economies of scale and scope of the economy, especially the scope of economic effects. Regional agricultural product brand construction requires the leading enterprises to promote and gather the effect of leading enterprises as the core to promote agricultural industrialization, bulk purchase of production materials, focus on brand advertising, access to domestic and foreign advanced technology, unified research and development of new products or The quality of agricultural products to improve the full access to economies of scale and scope of the economy, reduce the cost of agricultural units, the market long-term competitive advantage.

Trademark infringement and seizure of geographical indications and other events are common. Chinese "Trademark Law" and "Trademark Law Implementation Rules" are on the trademark and geographical indications of registration and the right to maintain the corresponding legal requirements. Special attention is given to geographical indications as an independent intellectual property, with regional characteristics. The geographical indications registered by a State are generally only legally effective in their territory and are not recognized and protected by the laws of other countries abroad. Regional characteristics of agricultural products production and management enterprises in shaping the brand at the same time, to strengthen the brand's legal protection awareness, and actively carry out geographical indications of domestic and international registration, if encountered in the corporate brand rights and interests have been infringed, we must resolutely use domestic and international regulations and practices To protect their interests. Especially in the international market, with its passive to adapt to the rules, it is better to take the initiative to use the rules. Chinese geographical indications are often registered abroad, domestic enterprises to strengthen the protection of awareness, absorption of foreign advanced experience, good geographical indications at home and abroad registration and protection work. For example, the French wine complete geographical indications protection system, the United States Florida citrus, Thai rice and other geographical indication products have been registered in our country.

\section{Conclusion}

This paper analyzes the connotation of the brand, expounds the significance of the brand of 
agricultural products from the aspects of consumption, industrial cluster and enterprise development. On the basis of this, it is necessary to strengthen the brand awareness and enhance the product quality, the development of industrial clusters, a reasonable brand positioning, to take appropriate brand operating strategy.

\section{References}

[1] Ge Qi. New economic brand value of the core elements [J]. Economic Forum, 2007 (15)

[2] Xu Baiyuan. Chinese agricultural product quality and safety management problem analysis [J]. Macroeconomic Research, 2007 (03)

[3] Peng Yuliang. The issue of agricultural product quality management control [J]. Journal of Shandong Agricultural University (Natural Science Edition), 2006 (02)

[4] Qian Bingzhen. Construction of agricultural product quality and safety system [J]. Journal of Shandong Institute of Agricultural Administrators, 2006 (03)

[5] Tian Shiying. Chinese agricultural product quality and safety status and countermeasures [J]. China Agricultural Information, 2006 (02)

[6] Qiu Qi, Zhang Xudong. Thoughts on the construction of agricultural products brand [J]. Heilongjiang Social Sciences, 2005 (04) 